\title{
Catalysts NHI Thermochemical Systems FY 2009 Year-End Report
}

\author{
Daniel M. Ginosar
}

September 2009
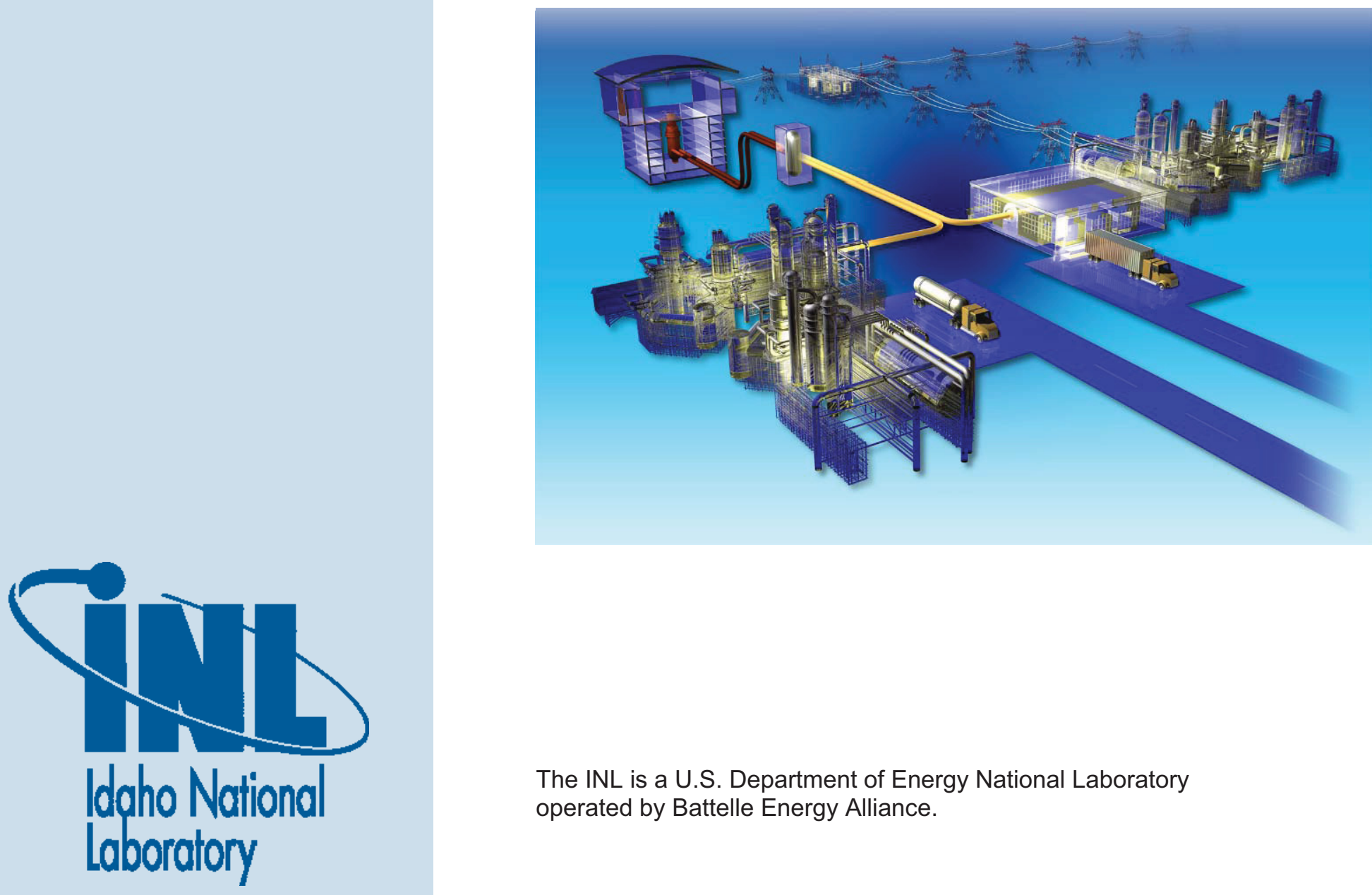

The INL is a U.S. Department of Energy National Laboratory operated by Battelle Energy Alliance. 


\section{DISCLAIMER}

This information was prepared as an account of work sponsored by an agency of the U.S. Government. Neither the U.S. Government nor any agency thereof, nor any of their employees, makes any warranty, expressed or implied, or assumes any legal liability or responsibility for the accuracy, completeness, or usefulness, of any information, apparatus, product, or process disclosed, or represents that its use would not infringe privately owned rights. References herein to any specific commercial product, process, or service by trade name, trade mark, manufacturer, or otherwise, does not necessarily constitute or imply its endorsement, recommendation, or favoring by the U.S. Government or any agency thereof. The views and opinions of authors expressed herein do not necessarily state or reflect those of the U.S. Government or any agency thereof. 


\title{
Catalysts \\ NHI Thermochemical Systems FY 2009 Year-End Report
}

\author{
Daniel M. Ginosar
}

September 2009

Idaho National Laboratory

Next Generation Nuclear Plant Project

Idaho Falls, Idaho 83415

Prepared for the

U.S. Department of Energy

Office of Nuclear Energy

Under DOE Idaho Operations Office

Contract DE-AC07-05ID14517 



\section{Next Generation Nuclear Plant Project}

\section{Catalysts \\ NHI Thermochemical Systems FY 2009 Year-end Report}

INL/EXT-09-16797

September 2009

Approved by:

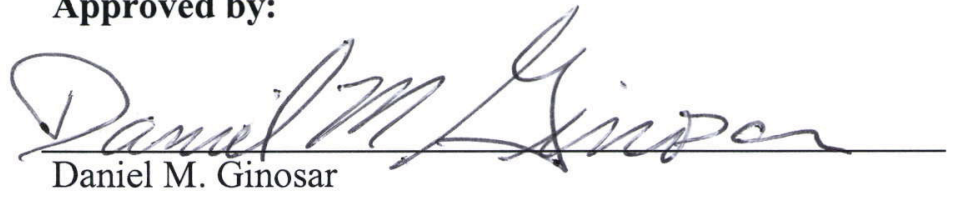

VHTR TDO Scientist

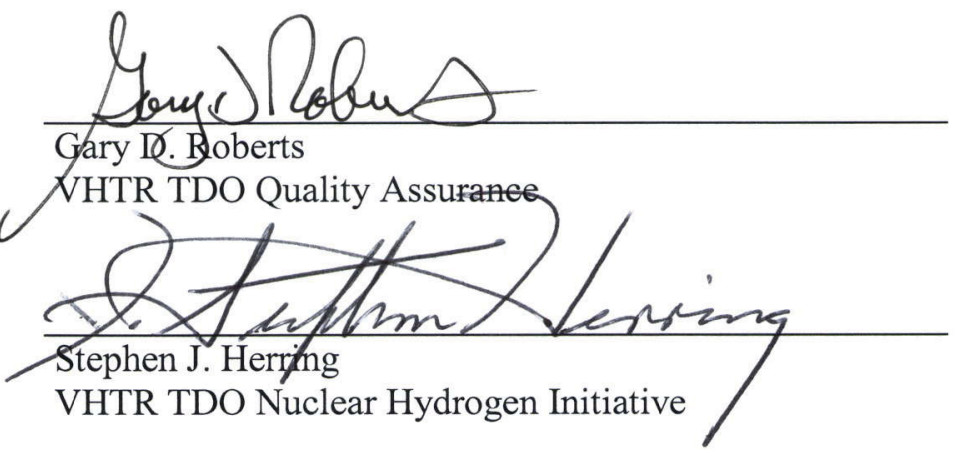

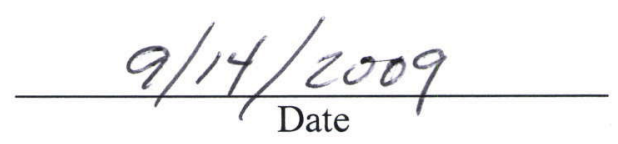

$\frac{9 / 14 / 2009}{\text { Date }}$

$9 / 15 / 2009$ 



\begin{abstract}
Work performed in the Catalyst project during FY 2009 focused on advanced catalysts for the decomposition of sulfuric acid, a reaction common to both the sulfur-iodine (S-I) cycle and the hybrid sulfur cycle. Catalyst work in FY 2009 included five tasks: development and testing of stabilized platinum based $\mathrm{H}_{2} \mathrm{SO}_{4}$ catalysts, development and testing of metal oxide based $\mathrm{H}_{2} \mathrm{SO}_{4}$ catalysts, support of the ILS for catalyst studies, conducting a long term catalyst stability test at anticipated operating temperatures and pressures, and developing capabilities for conducting pressurized catalyst tests.
\end{abstract}




\section{CONTENTS}

ABSTRACT.

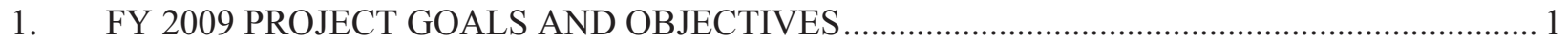

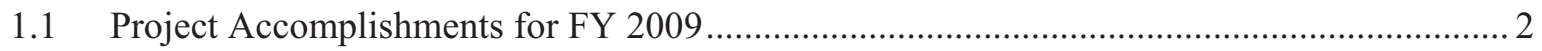

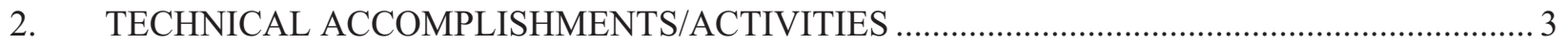

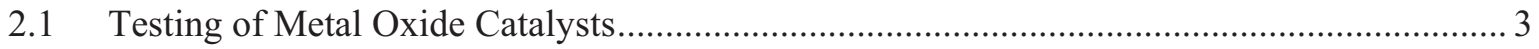

2.2 Catalyst Longevity Test at Elevated Pressures .............................................................. 4

2.2.1 High Pressure System Design and Construction..................................................... 4

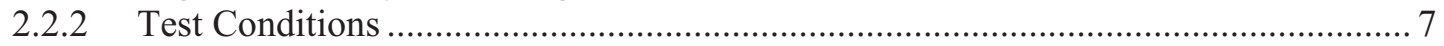

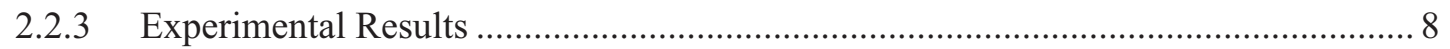

2.2.4 Test System Improvements for Pressurized Operation ....................................... 11

2.3 Testing Stabilized Platinum Based Catalysts ..................................................................... 12

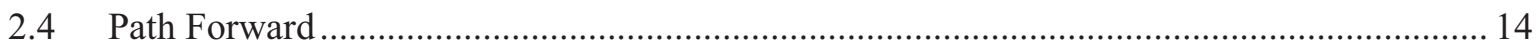

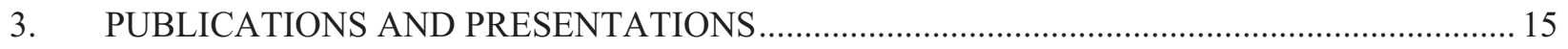

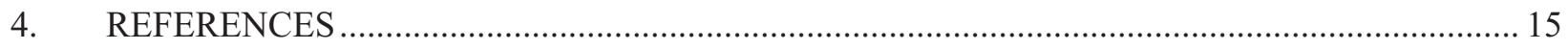

\section{FIGURES}

Figure 1. Catalytic activity of selected rate-earth metal oxides based on $\mathrm{SO}_{2}$ production rates................. 4

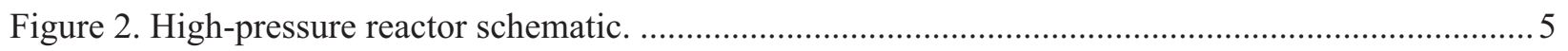

Figure 3. Ring collar on quarts tube (left). Collar tube with nylon nut, nylon/Teflon ferrule, and

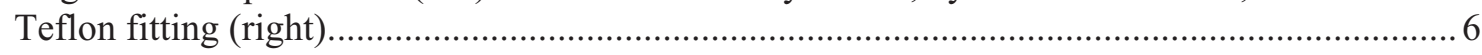

Figure 4. Equilibrium conversion of sulfuric acid to $\mathrm{SO}_{2}$ and $\mathrm{O}_{2}$ as a function of temperature and

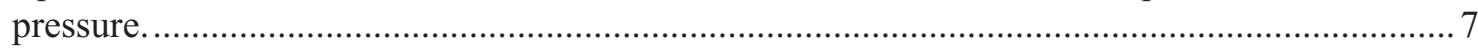

Figure 5. Reactor temperature downstream of the catalyst bed. ........................................................ 8

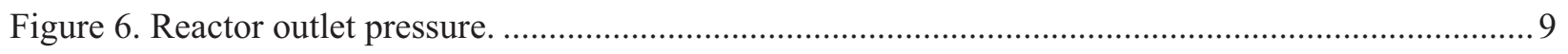

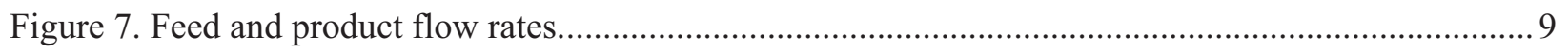

Figure 8. Product yields for sulfur-dioxide (pink) and oxygen (blue). ................................................. 10

Figure 9. Sulfuric acid feed rates using nitric acid treated stainless steel components............................ 11

Figure 10. $\mathrm{SO}_{2}$ yields at 0.9 and 30 bar pressure. Reaction conditions: $850^{\circ} \mathrm{C}, 0.25$ grams catalyst. ........ 12

Figure 11. $\mathrm{SO}_{2}$ yields over $\mathrm{Pt} / \mathrm{TiO}_{2}$ and $\mathrm{Ir}$ and $\mathrm{Ru}$ stabilized $\mathrm{Pt} / \mathrm{TiO}{ }_{2}$ catalysts at 30 bar, $850^{\circ} \mathrm{C}$, $78.4 \mathrm{wt} \% \mathrm{H}_{2} \mathrm{SO}_{4}$, and a WHSV $=400 \mathrm{acid} / \mathrm{g}$ catalyst $/ \mathrm{hr}$.

Figure 12. $\mathrm{SO}_{2}$ yields over $\mathrm{Pt} / \mathrm{TiO}_{2}$ and $\mathrm{Ir}$ stabilized $\mathrm{Pt} / \mathrm{TiO}_{2}$ catalysts at $30 \mathrm{bar}, 850^{\circ} \mathrm{C}, 78.4 \mathrm{wt} \%$ $\mathrm{H}_{2} \mathrm{SO}_{4}$, and a WHSV $=120 \mathrm{~g}$ acid $/ \mathrm{g}$ catalyst $/ \mathrm{hr}$...... 


\section{Catalysts NHI Thermochemical Systems FY 2009 Year-end Report}

\section{FY 2009 PROJECT GOALS AND OBJECTIVES}

Work performed in the Catalysts project during FY 2009 focused on advanced catalysts for the decomposition of sulfuric acid, a reaction common to both the sulfur-iodine (S-I) cycle and the hybrid sulfur cycle. Efforts in this project from prior years have found that, although platinum supported on titanium oxide will be an acceptable catalyst for sulfuric acid decomposition in the integrated laboratory scale (ILS) project, the material has short comings, including significant cost and high deactivation rates because of sintering and platinum evaporation. Therefore, the catalyst stability needs to be improved significantly for pilot- and larger-scale systems.

Work in FY 2008 found that, at atmospheric pressure, deactivation rates of a $1 \mathrm{wt} \%$ platinum catalyst could be reduced by $300 \%$ by adding either $0.3 \mathrm{wt} \%$ iridium (Ir) or $0.3 \mathrm{wt} \%$ ruthenium (Ru) to the catalyst. Work in FY 2009 focused on examining the platinum group metal catalysts activity and stability at elevated pressures. Simple and complex metal oxides are also known to catalyze the sulfuric acid decomposition reaction. These metal oxides could offer activities comparable to platinum but at a significantly reduced cost. Thus, a second focus for Fiscal Year 2009 was to explore metal oxide catalysts for the sulfuric acid decomposition reaction.

Work in FY 2007 identified several commercial activated carbons for the HI decomposition reaction; a reaction specific to the S-I cycle. Those materials should be acceptable for the pilot-scale project. The activated carbon catalysts have some disadvantages, including low activity at the lower range of reactor operating temperature $\left(350\right.$ to $\left.400^{\circ} \mathrm{C}\right)$ and a propensity to generate carbon monoxide in the presence of water that could contaminate the hydrogen product. This focus area had a low priority in FY 2009 because of limited funding.

Catalyst work in FY 2009 included five tasks: development and testing of stabilized platinum based $\mathrm{H}_{2} \mathrm{SO}_{4}$ catalysts, development and testing of metal oxide based $\mathrm{H}_{2} \mathrm{SO}_{4}$ catalysts, support of the ILS for catalyst studies, conducting a long term catalyst stability test at anticipated operating temperatures and pressures, and developing capabilities for conducting pressurized catalyst tests.

FY 2009 activities are:

1. Development and testing of stabilized platinum based $\mathrm{H}_{2} \mathrm{SO}_{4}$ catalyst

2. Catalyst longevity testing

3. Improve capabilities for pressurized catalyst tests

4. Testing metal oxide based $\mathrm{H}_{2} \mathrm{SO}_{4}$ catalysts

5. Support of the ILS for catalyst studies.

FY 2009 Level 2 Milestones are:

1. Complete catalyst longevity test

2. Complete testing of advanced catalysts for $\mathrm{H}_{2} \mathrm{SO}_{4}$ decomposition.

FY 2009 Level 2 Deliverables are:

1. Draft report on catalyst longevity test 
2. Draft year-end report on FY 2009 activities.

\subsection{Project Accomplishments for FY 2009}

Technical accomplishments for 2009 are as follows:

- Seven rare-earth metal oxides were examined for their ability to catalyze the decomposition of sulfuric acid.

- A catalyst test system was modified for pressurized experiments.

- A longevity test was performed using a $1 \mathrm{wt} \% \mathrm{Pt} / \mathrm{TiO}_{2}$ catalyst.

- Three platinum based catalysts were tested at elevated pressure.

- The pressurized system was upgraded to improve system stability.

Nontechnical accomplishments in FY 2009 included:

- Providing a presentation at the American Institute of Chemical Engineers annual meeting in Philadelphia, November 17 to 21, 2008, and chairing two sessions on Nuclear Hydrogen Production at that American Institute of Chemical Engineers meeting

- Providing a presentation at the American Chemical Society National meeting in Salt Lake City, Utah, March 20-26, 2009

- Providing a presentation at the North American Catalysis Society Meeting, in San Francisco, June 8-12, 2009.

- Three papers were published on the catalyst research: two in the International Journal of Hydrogen Energy and one in Catalysis Today. A list of publications and presentations are provided at the end of this report. 


\section{TECHNICAL ACCOMPLISHMENTSIACTIVITIES}

\subsection{Testing of Metal Oxide Catalysts}

Metal oxides may provide an attractive alternative to platinum-based catalysts for the decomposition of sulfuric acid. However, all the materials examined so far displayed limitations, including material sintering, phase changes, low activity due to sulfate formation, and, in the case of some complex metal oxides, decomposition to their individual oxides. Sulfate formation may not always be detrimental to catalyst activity. Tagawa and Endo ${ }^{1}$ have proposed that metal oxides catalyze the decomposition of sulfuric acid by repetition of the following reactions:

$$
\begin{aligned}
& \mathrm{MO}+\mathrm{SO}_{3} \rightarrow\left(\mathrm{MSO}_{4}\right) \rightarrow \mathrm{MO}_{2}+\mathrm{SO}_{2} \\
& \mathrm{MO}_{2} \rightarrow \mathrm{MO}+1 / 2 \mathrm{O}_{2}
\end{aligned}
$$

where $\mathrm{MO}$ and $\mathrm{MO}_{2}$ are the reduced and oxidized forms of the metal oxide catalyst.

Consequently, an oxide catalyst for this reaction should (i) have the capability of forming a sulfate $\left(\mathrm{MSO}_{4}\right)$ intermediate with the incoming $\mathrm{SO}_{3}$, and (ii) easily decompose the sulfate to the final products of $\mathrm{SO}_{2}$ and $1 / 2 \mathrm{O}_{2}$, regenerating the initial form of the oxide. Experimental results suggest that significant catalytic activity is possibly due to the metal oxide having an optimum in oxide/sulfate transition temperature under a given reaction pressure. ${ }^{1}$

Three characteristics make rare-earth metal oxides appealing catalyst candidates for decomposing sulfuric acid: their high melting points, which provide a potentially attractive property to limit sintering; their capability to exist in more than one oxidation state; and their rich sulfate formation chemistry. Their adequacy will be determined, at least in part, by their sulfate/oxide transition temperature under the pressures and concentrations applied to the sulfuric acid decomposition reaction. Comparison of different literature reports did not show complete agreement on rare-earth sulfate formation and/or decomposition temperatures. Wide temperature ranges were reported in most cases.

The following rare-earth metal oxides were examined for their ability to catalyze the decomposition of sulfuric acid: $\mathrm{CeO}_{2}, \mathrm{Sm}_{2} \mathrm{O}_{3}, \mathrm{Eu}_{2} \mathrm{O}_{3}, \mathrm{Gd}_{2} \mathrm{O}_{3}, \mathrm{~Tb}_{2} \mathrm{O}_{3}, \mathrm{Dy}_{2} \mathrm{O}_{3}$, and $\mathrm{Ho}_{2} \mathrm{O}_{3}$. Experiments were conducted at atmospheric pressure, a weight hourly space velocity (WHSV) of approximately $250 \mathrm{~g} \mathrm{acid} / \mathrm{g}$ catalysts/hour, and at temperatures between 650 and $900^{\circ} \mathrm{C}$. Catalytic activities, base on $\mathrm{SO}_{2}$ production rates are shown in Figure 1. Of the oxides, only cerium oxide showed activity significantly greater than the blank experiment. However, ceria catalytic activity was much lower than activities measured using platinum group metal based catalysts.

Samples were examined after reaction by temperature programmed desorption, diffuse reflectance inferred spectroscopy, and X-ray power diffraction. These analyses showed that, except for ceria, these samples formed stable sulfates that could only be desorbed at very high temperatures (in excess of $1,000^{\circ} \mathrm{C}$ ). Thus, these examined metal oxides are not acceptable candidates to replace platinum group metal catalysts. However, ceria may have potential, in light of recent efforts to improve its catalytic properties by doping it with specific elements. There has been an interest in ceria and ceria doped with elements such as zirconium, lanthanum, yttrium, and gadolinium to improve catalytic activity and stability; for example, see Zhao and Gorte. ${ }^{2}$ 


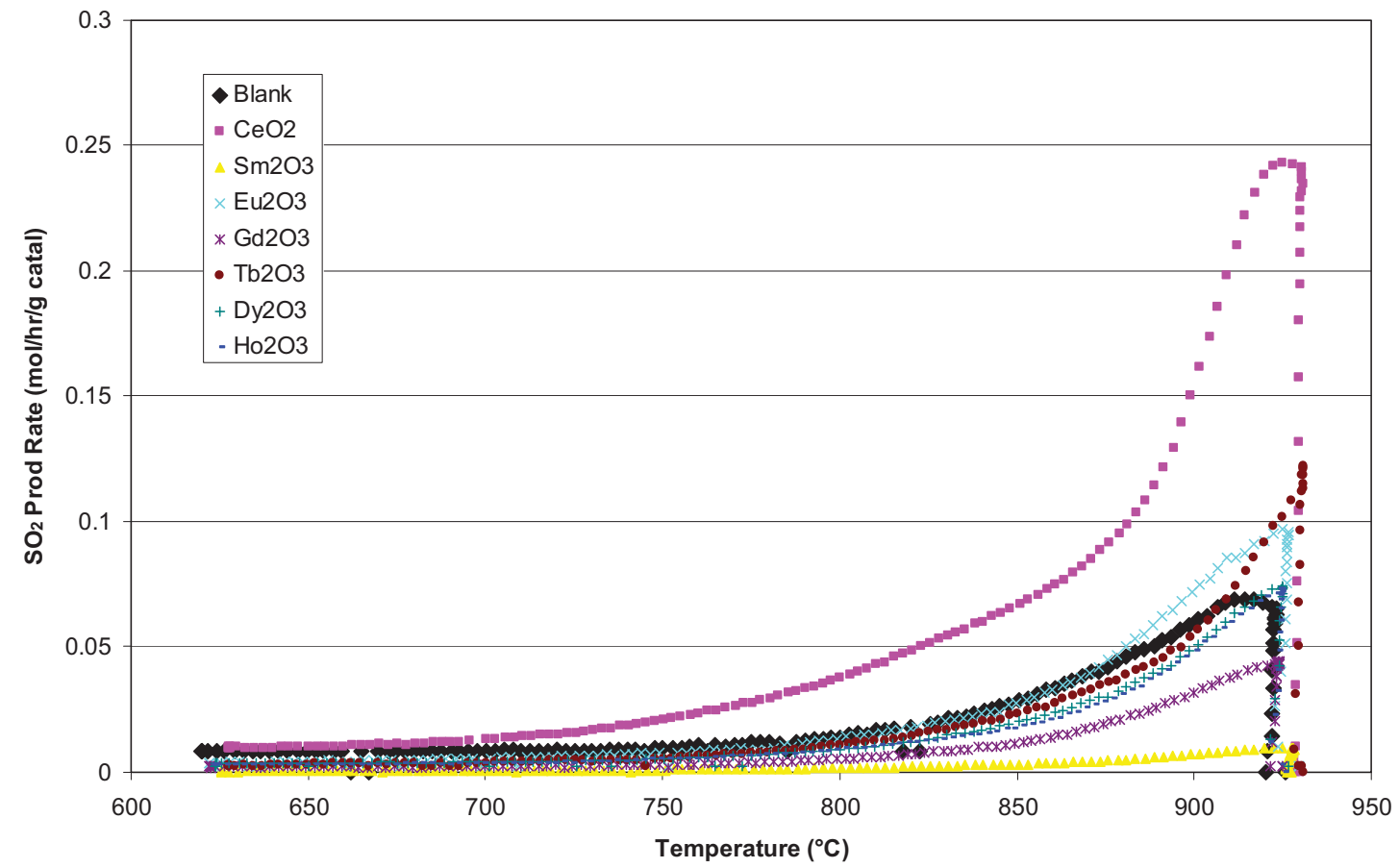

Figure 1. Catalytic activity of selected rate-earth metal oxides based on $\mathrm{SO}_{2}$ production rates.

\subsection{Catalyst Longevity Test at Elevated Pressures}

To support the Nuclear Hydrogen Initiative's (NHI) hydrogen technology down selection process, information on catalyst longevity was required. The goal of the longevity test was to determine if the catalyst displayed a deactivation rate of less than $10 \%$ per 1,000 hours of operation at anticipated commercial operating conditions.

In previous years, INL conducted atmospheric pressure tests for 31 days, or 744 hours, using the 1\% $\mathrm{Pt} / \mathrm{TiO}_{2}$ and the $0.3 \% \mathrm{Ru}-1 \% \mathrm{Pt} / \mathrm{TiO}_{2}$ catalysts run at similar conditions as the S-I ILS system (expect for pressure). Catalyst deactivation was not observed in those studies,. This result was anticipated because of the excess amount of catalyst that was engineered into the S-I ILS.

In the pilot-plant and larger-scale systems, including a commercial water splitting process, the reaction is anticipated to operate at elevated pressures. Thus, meaningful catalyst longevity data had to be obtained at pressurized conditions. To conduct the pressurized test, the catalyst test system needed to be modified for pressurized operation.

\subsubsection{High Pressure System Design and Construction}

The high-pressure catalyst test system design was similar to the atmospheric pressure test system previously used with some significant changes (see Figure 2). All tubing and fittings that could come in contact with pressurized gas or acid were to be rated to $1,500 \mathrm{psi}$, and items in contact with acid had to be corrosion resistant. The materials compatible with concentrated acid up stream of the reactor were different then the materials compatible with the more dilute acid exiting the reactor. The previous system used Teflon tubing and fittings, but those parts were rated to a maximum pressure of $150 \mathrm{psi}$, and the pump employed was a peristaltic pump supplied with a Teflon pump tube that had a maximum outlet pressure rating of 100 psi. 


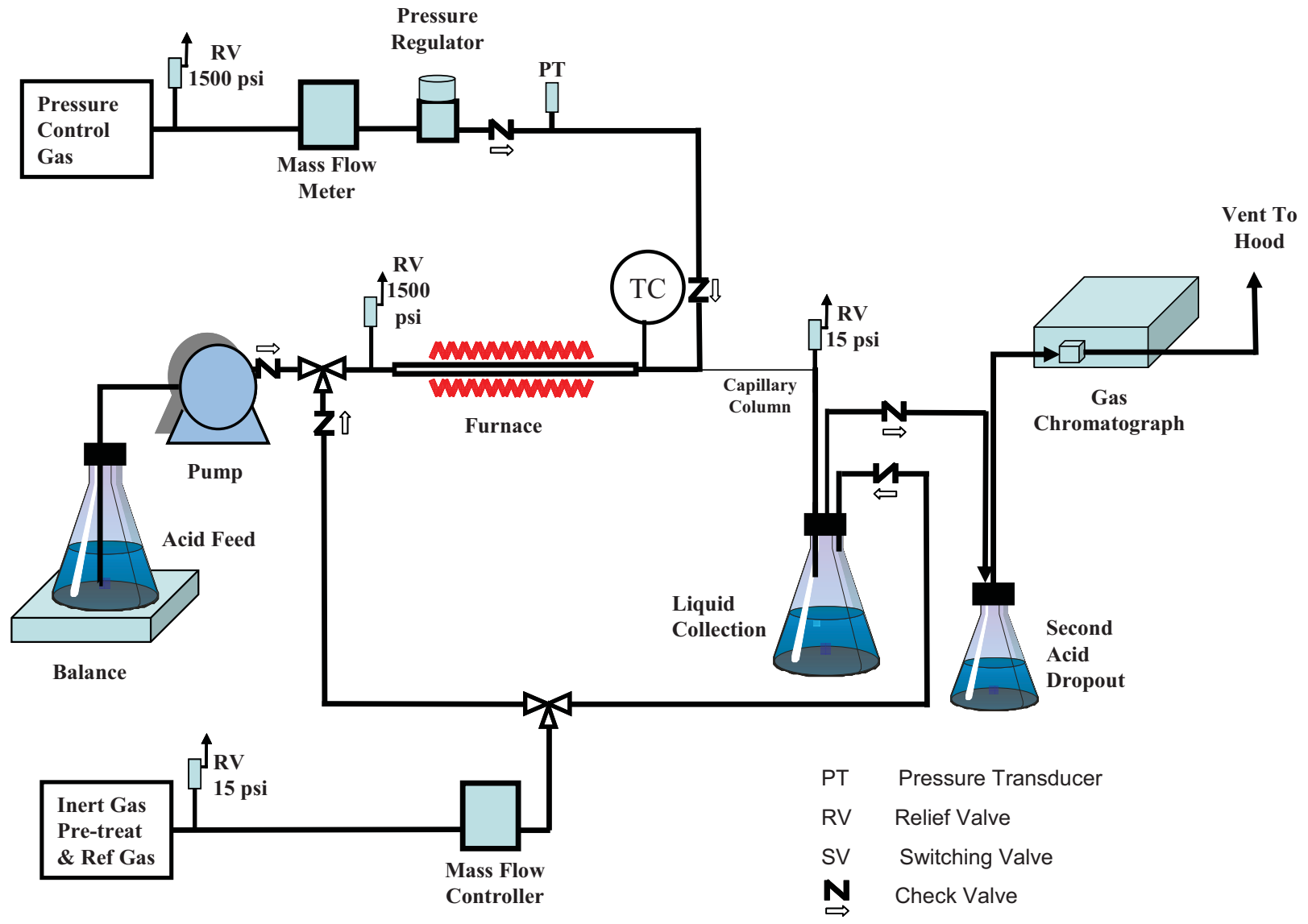

Figure 2. High-pressure reactor schematic.

The pump was replaced with a positive displacement piston driven pump commonly used in high-performance liquid chromatography. All seals were replaced with acid compatible materials, and the stainless steel pump head, check valves, and fittings were coated with silicon by SilcoTeck (Bellefonte, PA). Similarly, the pressure relief valve was made from stainless steel and was coated with silicon by SilcoTeck.

The lower concentration of acid downstream of the reactor was significantly more corrosive than the upstream acid. Silicon treated stainless steel was not compatible for that application, and metal parts compatible with that stream were either Inconel or Hastelloy. An alternative material, Tefzel ${ }^{\circledR}$, was found to posses the needed chemical stability and pressure rating. Tefzel ${ }^{\circledR}$ is an inert fluoropolymer that can withstand higher pressures than Teflon. Thick walled, 1/16 in. OD (outer diameter) by $0.01 \mathrm{in.}$ ID (inner diameter) tubing is rated to 4,000 psi. Wherever possible, thick walled $1 / 16$ in. OD Tefzel ${ }^{\circledR}$ tubing and fittings were used.

An additional challenge encountered in the design of the high-pressure system was the reactor material. Previous work at Sandia National Laboratory and the Idaho National Laboratory could not identify a corrosion resistant metal acceptable for that application. Two options have been proven to work; silica carbide and quartz. However, for both applications, compression fittings that "bite" into the tubing would cause cracking, an unacceptable outcome. Due to the INL team's experience with high pressure quartz windows and tubing, quartz was chosen. 
Numerous flange/fitting designs were attempted but proved to be too fragile. The final design used a ring collar in the quartz tube with Teflon fittings, as shown in Figure 3. Since the Teflon ferrules cannot bite into the quartz tube, they slip off under pressure. The ring collar ensures that the Teflon fitting system does not slip off. The current system is an intermediate step toward a final design. The Teflon is not rated to high pressures, but seals relatively well up to 500 psi. Due to the cold flow nature of Teflon, the fittings need to be tightened every few days.

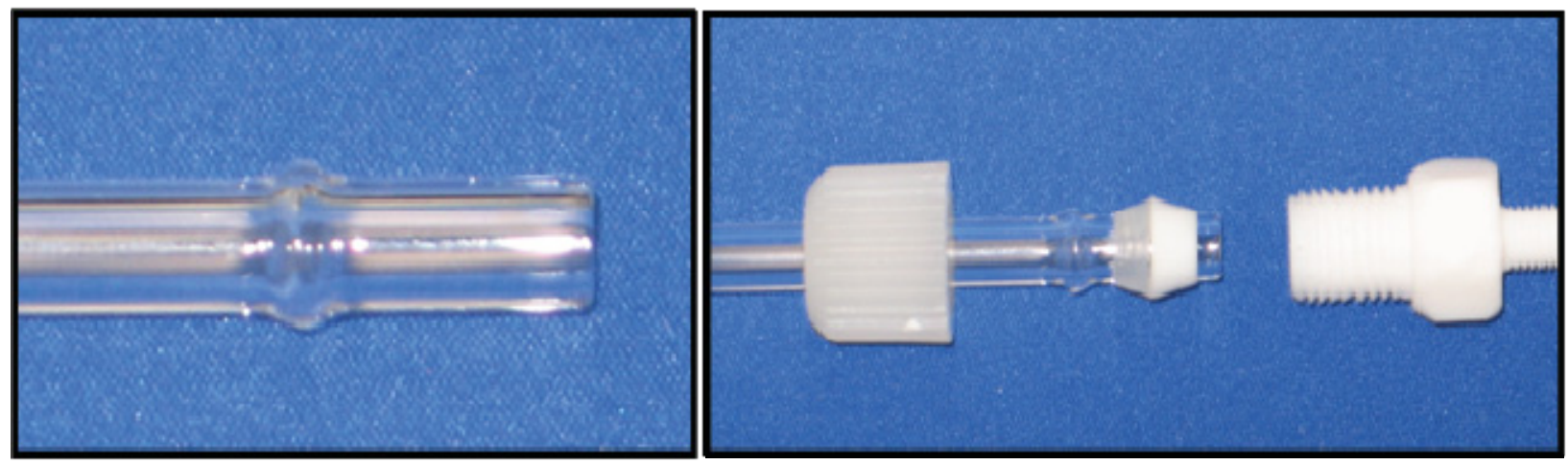

Figure 3. Ring collar on quarts tube (left). Collar tube with nylon nut, nylon/Teflon ferrule, and Teflon fitting (right).

The final system modification needed was a pressure control system. A 2 meter, 150 micron fused silica capillary column was used to provide a flow restriction. Argon gas, set at the test pressure using a pressure regulator, mixed with the reactor effluent and the combined gas and liquid stream flowed through a 2 micron hastelloy filter frit and then through the capillary column. The compounds exiting the column entered the first liquid collection vessel at atmospheric pressure. Production rates of oxygen and $\mathrm{SO}_{2}$ are monitored by on-line gas chromatography. Concentrations of the product gases and a reference gas (helium) are monitored to determine molar production rates of the products.

The reaction takes place across a bed of catalysts located inside the quarts tube reactor. The tube reactor dimensions are $6 \mathrm{~mm}$ OD by $4 \mathrm{~mm}$ ID with a length of $90 \mathrm{~cm}$. Upstream of the catalyst bed, the reactor is filled with 20 to 40 mesh $(0.425-0.85 \mathrm{~mm})$ quartz chips to promote heat transfer and provide nucleation sites for acid boiling. The catalyst employed was supplied by Johnson Matthey with a particle size between 40 and 60 mesh $(0.250-0.425 \mathrm{~mm})$. A $2 \mathrm{~mm}$ OD quartz thermowell was inserted inside the reactor with the end located at the exit of the catalyst bed. An "X" shaped quartz spacer was welded to the thermowell to insure that the end did not touch the reactor wall, but was situated in the gas flow path. A narrow diameter type $\mathrm{K}$ thermocouple was place inside the thermowell and used to monitor reactor temperature.

The tube reactor was placed inside a standard single zone 18 -in.-tube furnace with a 1 in. ID. A 6-in.long heating mantel was wrapped around the reactor tube upstream of the furnace and heated to approximately $500^{\circ} \mathrm{C}$ to provide a vaporization region. The gap between the $6 \mathrm{~mm}$ reactor tube and the 1 -in. furnace opening was filled with high-temperature insulation.

Significant safety systems put in place included use of a mechanical pressure relief valve to protect the system from overpressure, a double barrier between the quartz tube and lab personal, and a hood flow interlock that shut down the test system if hood flow stopped. 


\subsubsection{Test Conditions}

The following set of experimental conditions was chosen for the 1,000 hour sulfuric acid decomposition catalyst longevity test:

- Catalyst Reaction Temperature $-825^{\circ} \mathrm{C}$

- Pressure-30 bar

- Acid Concentration-40 mole\% (78.4 wt\%)

- WHSV-18 $\mathrm{g} \mathrm{H}_{2} \mathrm{SO}_{4} / \mathrm{g}$ catalyst/hour

- Catalyst-1 wt $\%$ platinum supported on titanium oxide.

These conditions were chosen following discussions and e-mails with potential stake holders in the NHI program.

The temperature of $825^{\circ} \mathrm{C}$ was chosen as a compromise between the desire to have a high reactor outlet temperature and the limits that the Next Generation Nuclear Plant Project is facing.

The pressure of 30 bar provides an equilibrium limited conversion of $46.8 \%$ at $825^{\circ} \mathrm{C}$ (see Figure 4 ). This is slightly less than the $48.4 \%$ conversion used in the most recent S-I process model completed by Savanna River National Laboratory based on chemical reactor condition of about $870^{\circ} \mathrm{C}$ and 85 bar.

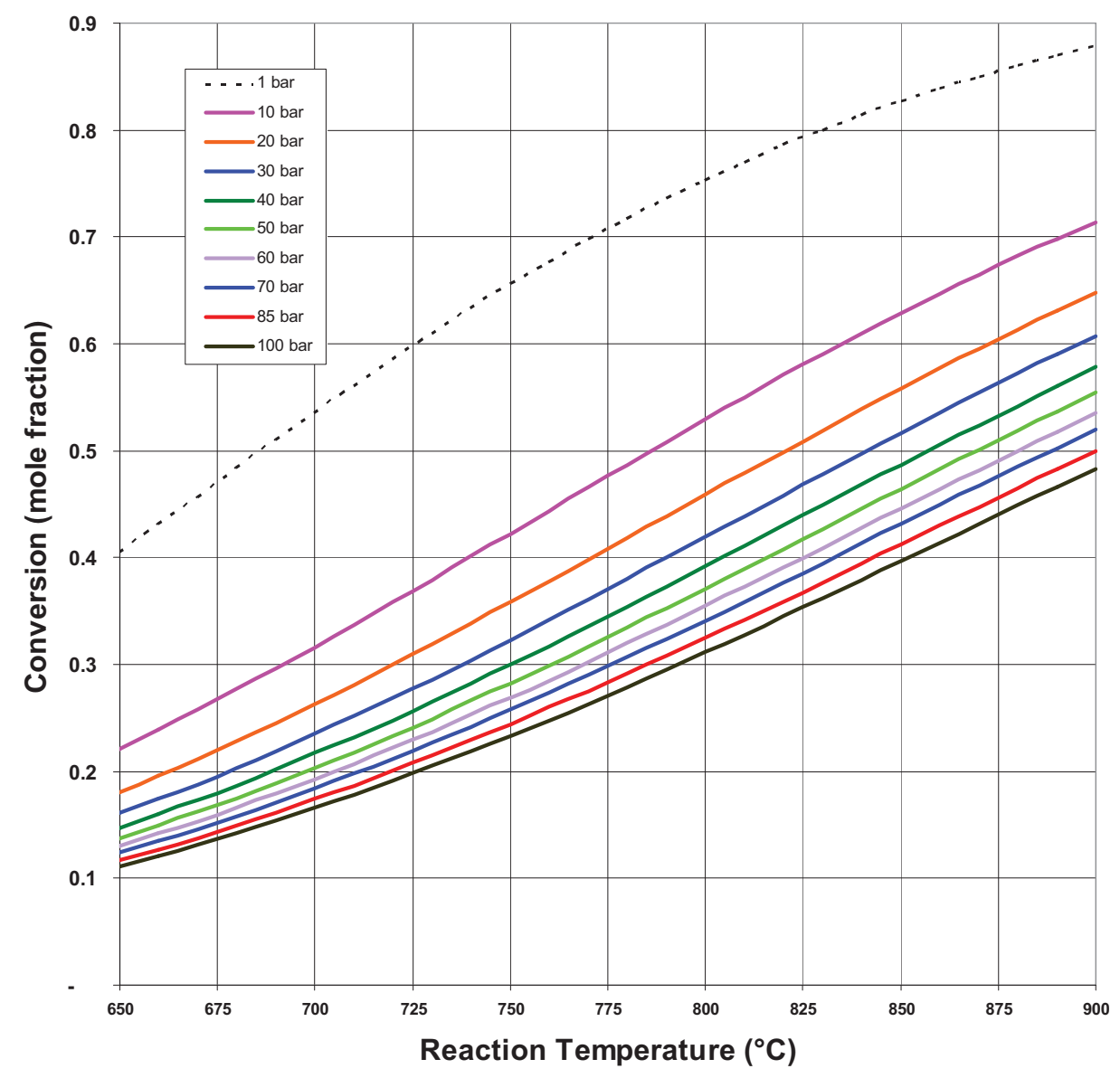

Figure 4. Equilibrium conversion of sulfuric acid to $\mathrm{SO}_{2}$ and $\mathrm{O}_{2}$ as a function of temperature and pressure. 
The 40 mole $\%$ sulfuric acid concentration is based on the S-I ILS conditions as well as the recent ASPEN process model.

The WHSV is based on the highest rates run previously at INL during 1-month long atmospheric pressure tests. This space velocity is twice the value used in the S-I ILS system. Thus, this experiment used half the quantity of catalysts used in the ILS for the same acid feed rate.

The catalyst chosen was a $1 \mathrm{wt} \% \mathrm{Pt} / \mathrm{TiO}_{2}$ catalyst, which was chosen because so little is known about catalyst performance at elevated pressure. Our previous accelerated deactivation tests run at atmospheric pressure showed that the addition of $0.3 \mathrm{wt} \%$ of either $\mathrm{Ru}$ or $\mathrm{Ir}$ to the $1 \mathrm{wt} \% \mathrm{Pt} / \mathrm{TiO}_{2}$ catalyst decreased deactivation by a factor of 3 over 7 days of testing compared to Pt alone. However, higher pressures of oxygen may dramatically suppress the activity of Ru and Ir. Additionally, literature suggests that higher pressures of oxygen may dramatically increase Pt sintering. Further, at higher pressures, the $\mathrm{TiO}_{2} \mathrm{support}$ as well as platinum, ruthenium, or iridium may form sulfates and cause the catalyst to lose all activity.

\subsubsection{Experimental Results}

Reaction temperature and pressures are shown in Figure 5 and Figure 6. Feed and product flow rates in moles-per-hour are displayed in Figure 4. In all figures, the catalyst sample time on line has been adjusted to represent the actual time the catalyst sample was exposed to acid and temperature since the test system needed to shut down several times due to mechanical problems.

Figure 7 shows that the acid flow rate was highly variable. This variation was most likely caused by corrosion products interfering with the high-performance liquid chromatography pump check valves. These variations in feed rate resulted in variations in the rate of sulfur dioxide and oxygen production.

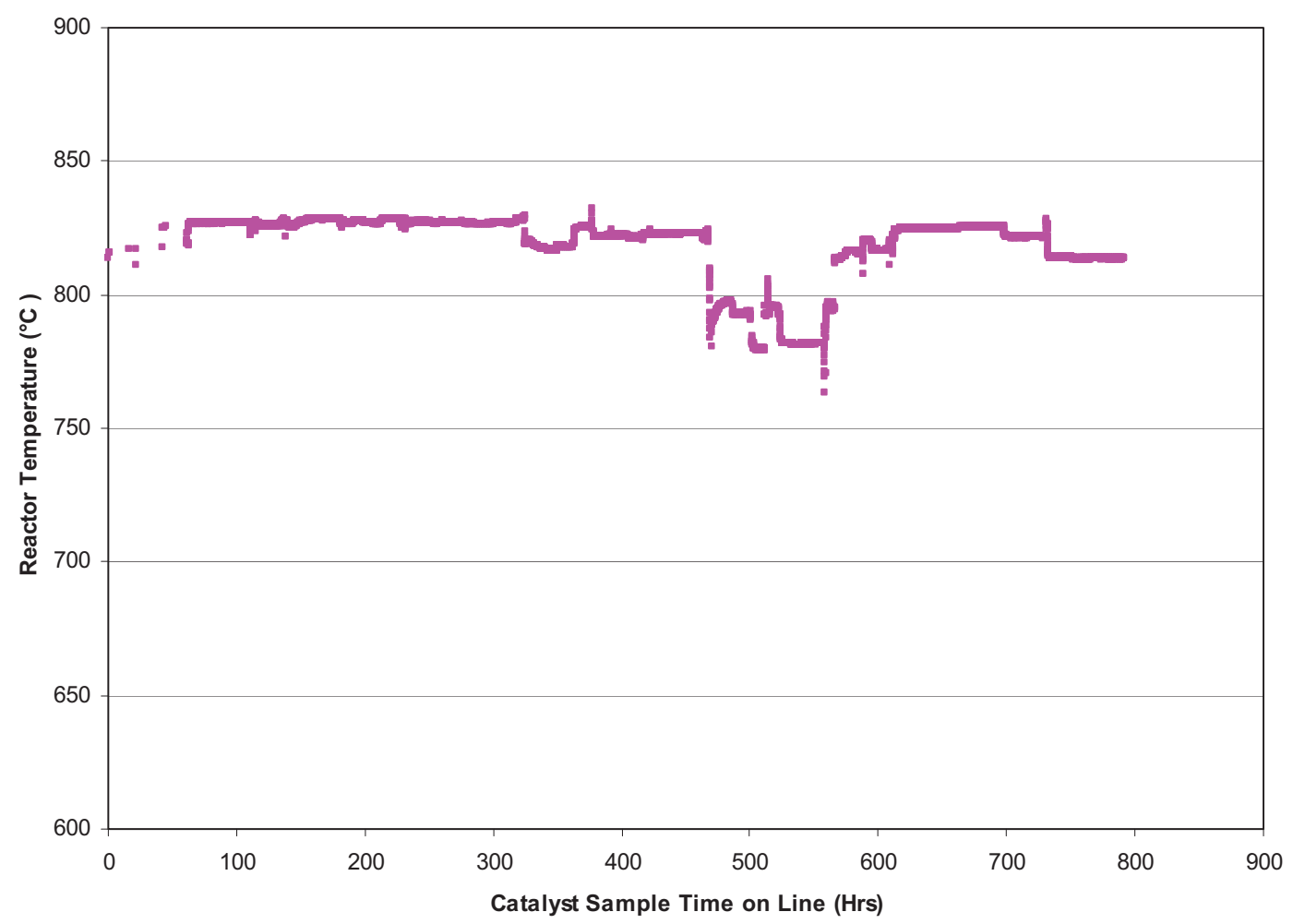

Figure 5. Reactor temperature downstream of the catalyst bed. 


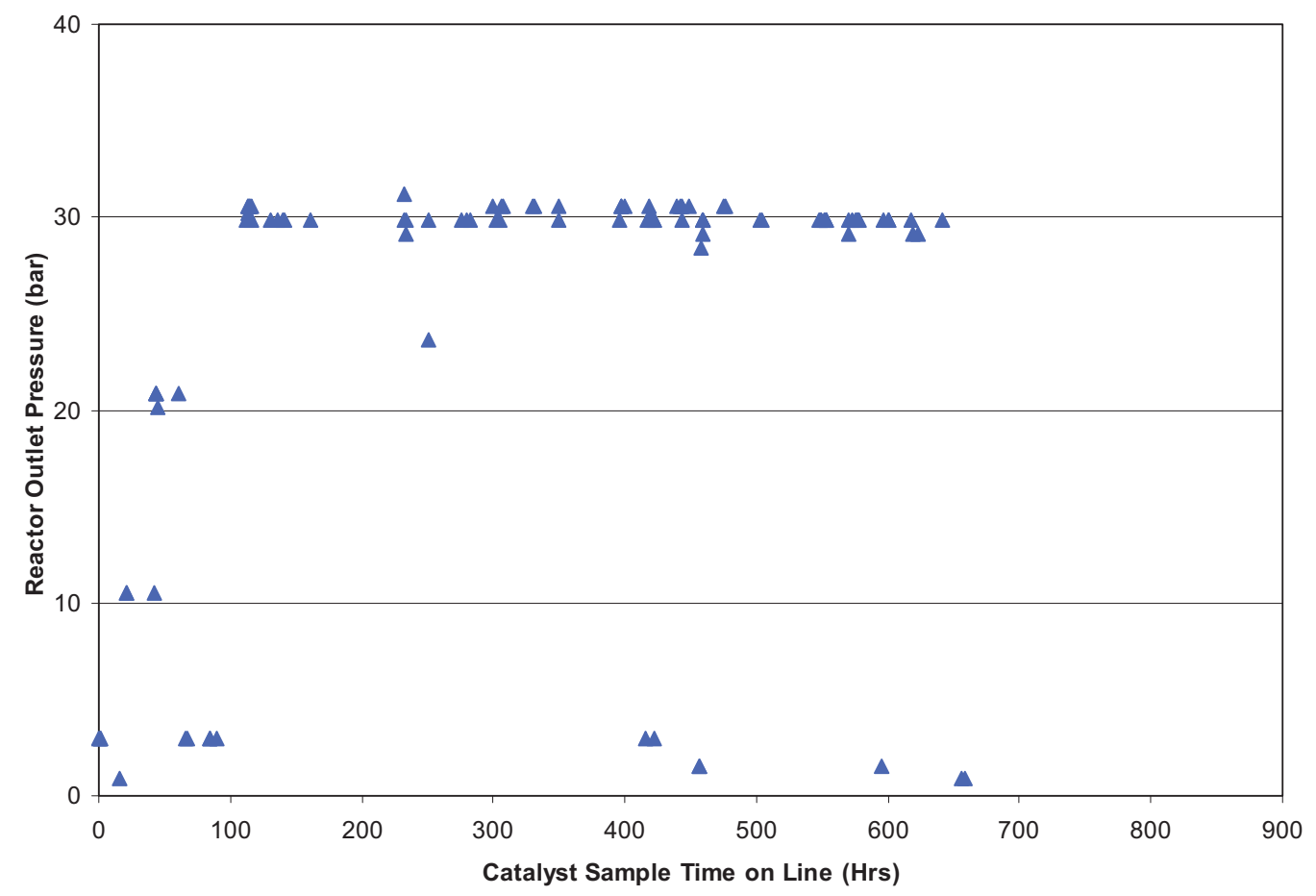

Figure 6. Reactor outlet pressure.

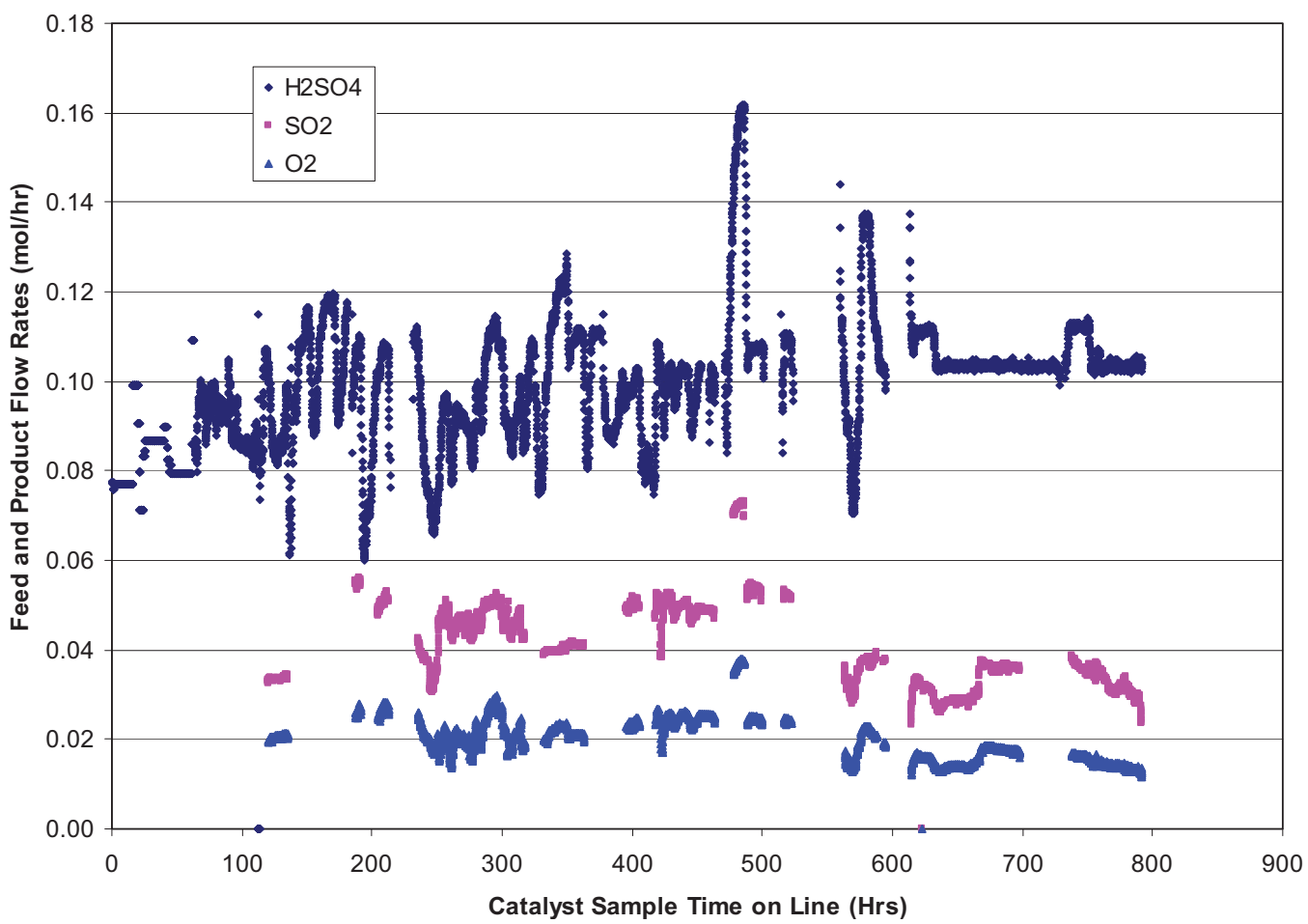

Figure 7. Feed and product flow rates. 
Product yields, shown in Figure 8, were calculated by dividing gas production rates by acid feed rates. Because of the significant variations in the acid feed rate, large variations in the calculated yields were obtained. Four distinct regions of product yield can be observed: a steady activity region between 0 and 480 hours, a declining region of activity from 480 hours to about 640 hours, a minor recovery period from 640 to 674 hours, and a continued deactivation period from 678 through the end of the experiment at 792 hours.

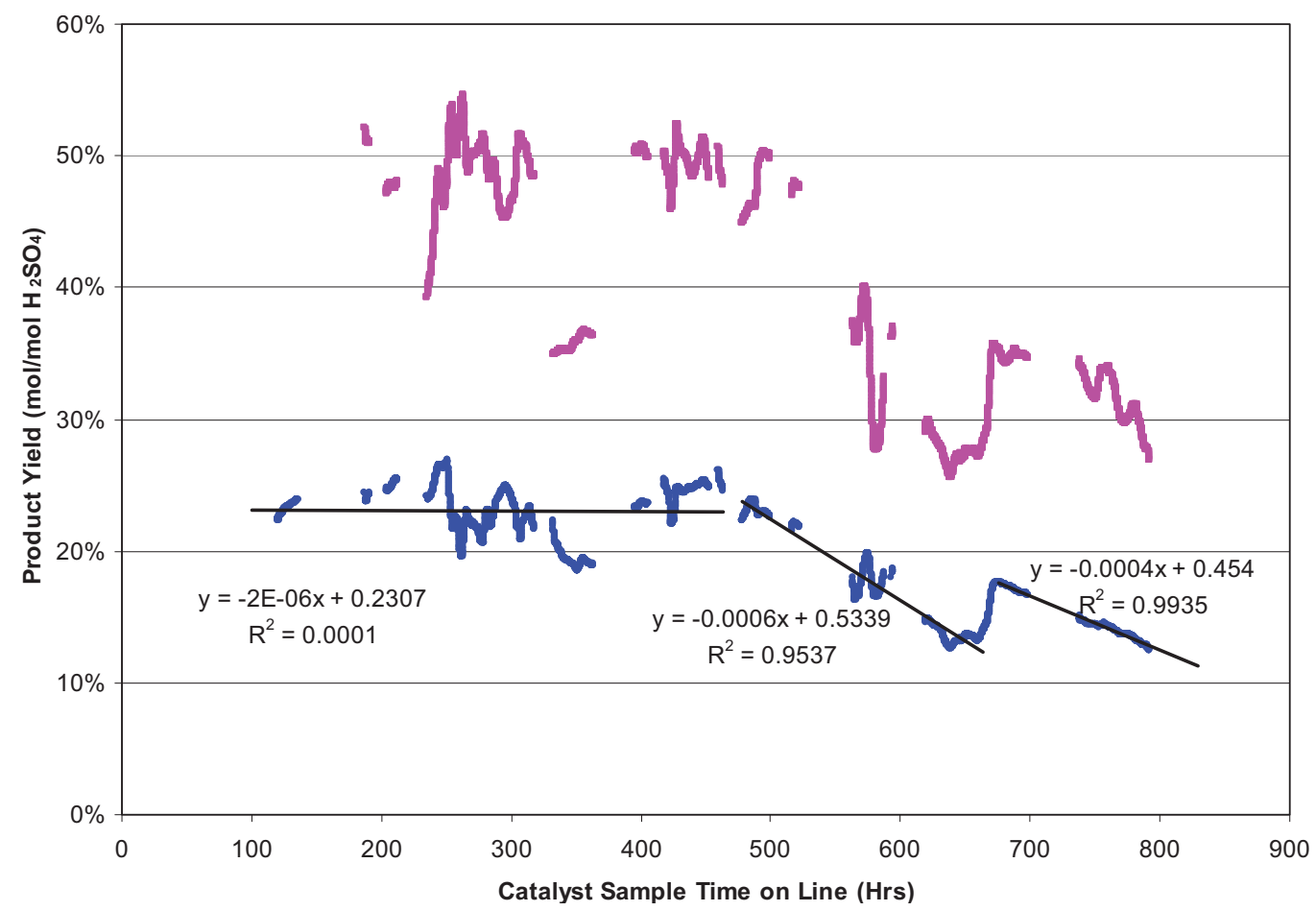

Figure 8. Product yields for sulfur-dioxide (pink) and oxygen (blue).

Between 0 and 480 hours, yields averaged $46.8 \%$ for sulfur-dioxide and $22.8 \%$ for oxygen. During this period of steady activity product yields were in good agreement with equilibrium values of $46.8 \%$ for sulfur-dioxide and $23.0 \%$ for oxygen. Yield standard deviations were $5.5 \%$ for sulfur-dioxide and $2.0 \%$ for oxygen. On a relative basis, the standard deviation for sulfur-dioxide was greater than oxygen. This would be expected because sulfur-dioxide has a moderate diffusion rate through Teflon and a significant solubility in the aqueous liquid acid collection. Thus, measurements of catalyst activity are more reliable using oxygen yield values. Linear regressions of product yields in this region found that the slopes were not statistically different than zero, with $\mathrm{R}^{2}$ values of 0.0015 for sulfur-dioxide and 0.0001 for oxygen.

After 480 hours, product yields declined. Using the oxygen data, catalyst activity was declining at a rate of $0.26 \%$ per hour relative to the average activity between 0 and 480 hours. At 640 hours, oxygen yield had declined to $13 \%$, or $56 \%$ of the initial level. A slight recovery period was observed between 640 and 674 hours, with oxygen yield increasing to $17.5 \%$, a level that still represented only $76 \%$ of initial catalyst activity. At 792 hours, the end of the experiment, oxygen conversion was $12.5 \%$ and declining, suggesting that catalyst activity at that point had decreased to $54 \%$ of the initial level.

The minor activity recovery period has been observed many times in previous experiments. After the brief recovery, the catalyst has always demonstrated continued deactivation. We believe that this minor recovery represents a change from one dominate rate controlling reaction mechanism to another, but the overall catalyst physical and chemical degradation processes are continuing and unchanged. 
Although this loss of activity is believed to representative of the material's behavior in the reaction environment, some contamination from corrosion of the silcosteel coated stainless steel may have affected catalyst stability.

\subsubsection{Test System Improvements for Pressurized Operation}

It was recognized that the capabilities to conduct sulfuric acid decomposition experiments at pressurized conditions was an important asset for the NHI. Thus, steps were taken to improve system reliability.

In the pressurized longevity experiment, three main operational problems were continually encountered: (1) significant pump rate variability, (2) plugging of the reactor inlet in the acid vaporization zone, and (3) leaking fittings. These issues could have been resolved if materials made of inconel, hastelloy, or Tefzel would have been used. However, many of the test system's wetted parts could not be obtained for the longevity test using the preferred materials because of time and budget limitations.

The variability in the pump flow rate was the most significant issue and appeared to be caused by contamination from the corrosion of the silcosteel coated stainless steel pump components interfering with the pump check valves. A short term solution was developed to reduce corrosion and improve pump stability. The silcosteel coated stainless steel parts were replace with standard stainless steel that had been exposed to $6 \mathrm{~N}$ nitric acid for 24 hours. Likewise, the steel relief valve wetted parts were treated with nitric acid under the same conditions. Sulfuric acid feed rates under conditions similar to the catalyst longevity test are shown in Figure 9. Compared to the feed rates observed during the catalyst longevity test (Figure 7) the nitric acid treated pump was much more stable than the silcosteel coated materials.

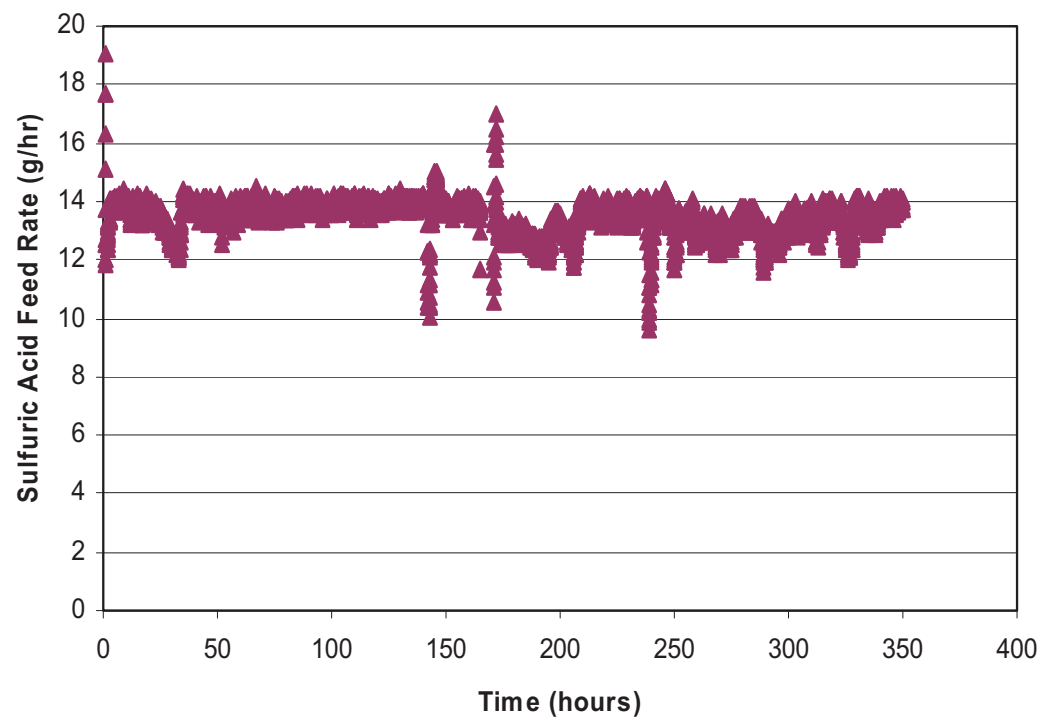

Figure 9. Sulfuric acid feed rates using nitric acid treated stainless steel components.

The nitric acid treatment of the steel components reduced the frequency, but did not eliminate the reactor plugging problems. Minor amounts of metal ions are dissolved into the concentrated sulfuric acid. These ions drop out of solution in the acid vaporization zone and plug the quartz chips that fill that region. To remedy this problem, the stainless steel parts need to be replaced with a material that has very low corrosion rates in concentrated sulfuric acid. The recommended metal is hastelloy. A hastelloy pump conversion kit was purchased from Teledyne Isco and a hastelloy over-pressure rupture head and disk was 
purchased from High Pressure Instruments. These parts will be available for installation if work continues in future fiscal years.

Leaks were minimized by replacing some Teflon fittings with components made from Tefzel. However, not all of the Teflon fittings could be replaced with commercially available components. To solve this issue, Tefzel bar stock and dowels were purchased. The INL research laboratory prototype shop can make custom fittings from the Tefzel stock material in order to replace all of the remaining Teflon components if work continues in future fiscal years.

\subsection{Testing Stabilized Platinum Based Catalysts}

During testing of the $\mathrm{Pt} / \mathrm{TiO}_{2}$ catalyst performed in $\mathrm{FY} 2008$ for 744 hours at atmospheric pressure, no loss in catalyst activity was observed. This is in direct contrast to the pressurized catalyst longevity test performed this fiscal year. These results suggest the importance of understanding catalyst stability under pressurized conditions.

A set of experiments was performed using the $\mathrm{Pt} / \mathrm{TiO}_{2}$ catalyst under atmospheric pressure and elevated pressure ( 30 bar) at a temperature of $850^{\circ} \mathrm{C}$ using 0.25 grams of catalyst. $\mathrm{SO}_{2}$ yields are shown in Figure 10. The increase in pressure resulted in lower yields of $\mathrm{SO}_{2}$. This set of results, along with information on the extended experiments ( $>700$ hours) conducted at atmospheric pressure and 30 bar, point to a more significant problem of catalyst deactivation at elevated pressure.

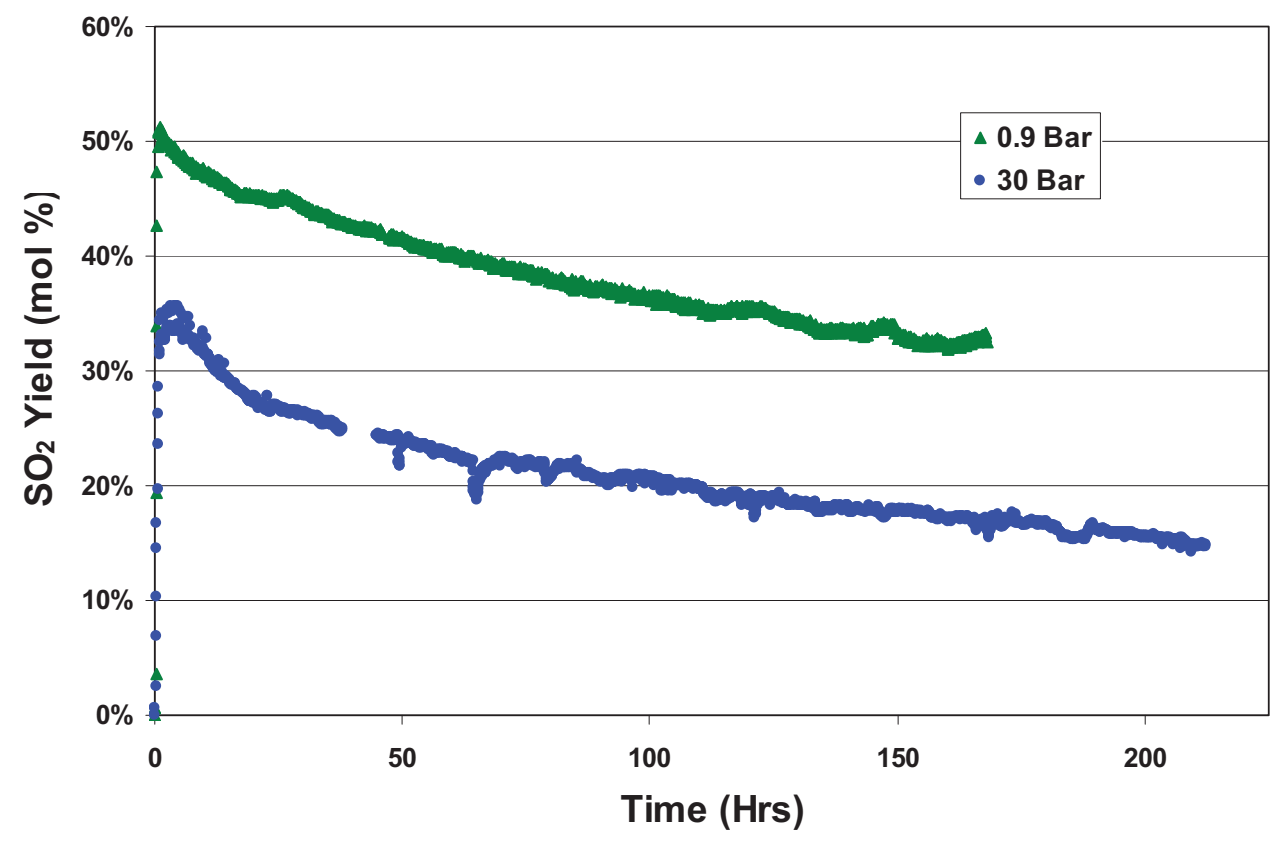

Figure $10 . \mathrm{SO}_{2}$ yields at 0.9 and 30 bar pressure. Reaction conditions: $850^{\circ} \mathrm{C}, 0.25$ grams catalyst.

Experiments run at atmospheric pressure in FY 2008 found that deactivation of a $1 \% \mathrm{Pt} / \mathrm{TiO}_{2}$ catalyst could be reduced by three-fold over 1 week of operation when $0.3 \mathrm{wt} \%$ or either $\mathrm{Ru}$ or $\mathrm{Ir}$ was added to the catalyst. A similar set of experiments were conducted at a pressure of 30 bars. Tests were conducted for up to 2 weeks at $850^{\circ} \mathrm{C}$ using $78.4 \mathrm{wt} \% \mathrm{H}_{2} \mathrm{SO}_{4}$ at a WHSV $=400 \mathrm{~g}$ acid/g catalyst $/ \mathrm{hr}$. $\mathrm{SO}_{2}$ yield results (Figure 11) did not show significant differences in end of run yields for the three different catalysts. The $\mathrm{Ru}$-Pt catalyst test was terminated early because of mechanical difficulties. 


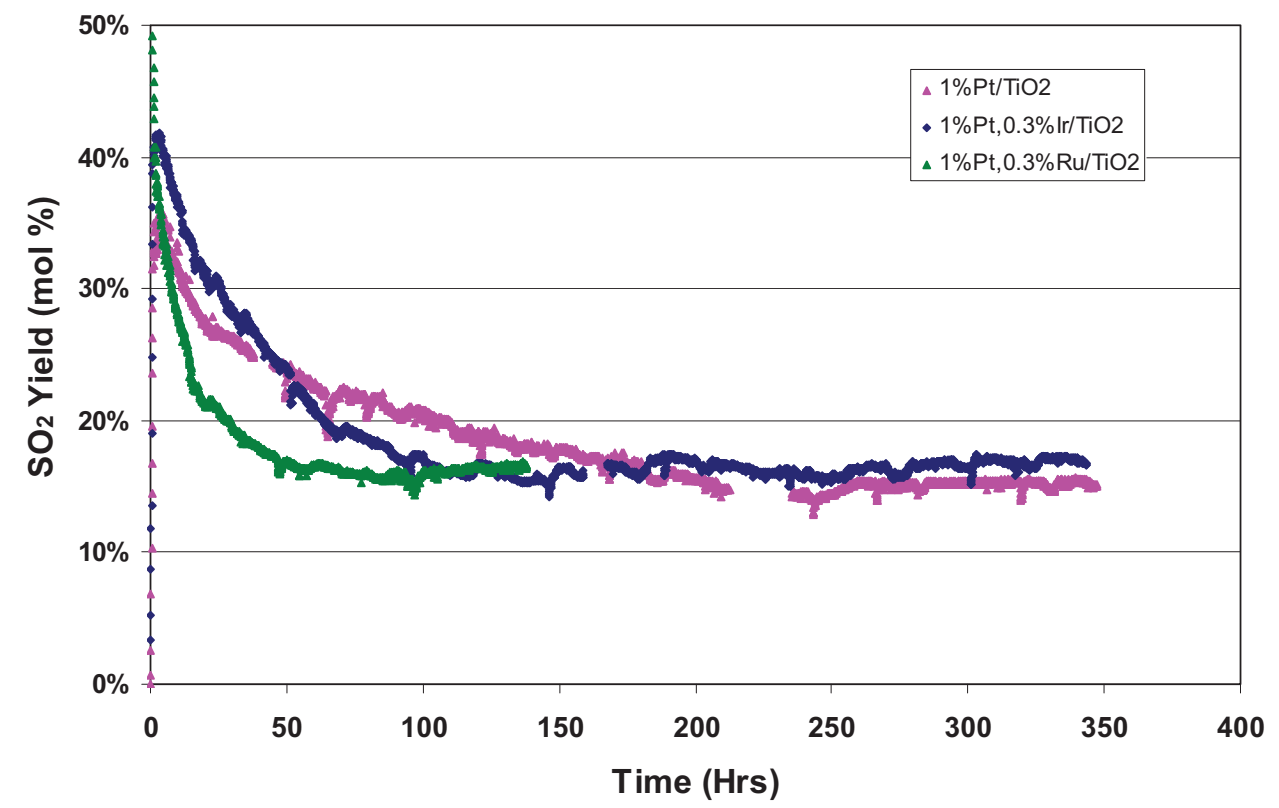

Figure 11. $\mathrm{SO}_{2}$ yields over $\mathrm{Pt} / \mathrm{TiO}_{2}$ and $\mathrm{Ir}$ and $\mathrm{Ru}$ stabilized $\mathrm{Pt} / \mathrm{TiO}_{2}$ catalysts at $30 \mathrm{bar}, 850^{\circ} \mathrm{C}, 78.4 \mathrm{wt} \%$ $\mathrm{H}_{2} \mathrm{SO}_{4}$, and a WHSV=400 acid/g catalyst/hr.

Since the end of run product yields were well below the anticipated pilot plant conditions, the set of experiments was rerun with a larger quantity of catalyst resulting in a lower WHSV of $120 \mathrm{~g}$ acid/g catalyst/hr. SO2 yields, shown in

Figure 12, were initially higher at the beginning of the experiment over the Ir stabilized catalyst but were not significantly different after 314 hours. Thus, the stabilizing materials that reduced deactivation rates at atmospheric pressure were not beneficial at the reaction pressure of 30 bar.

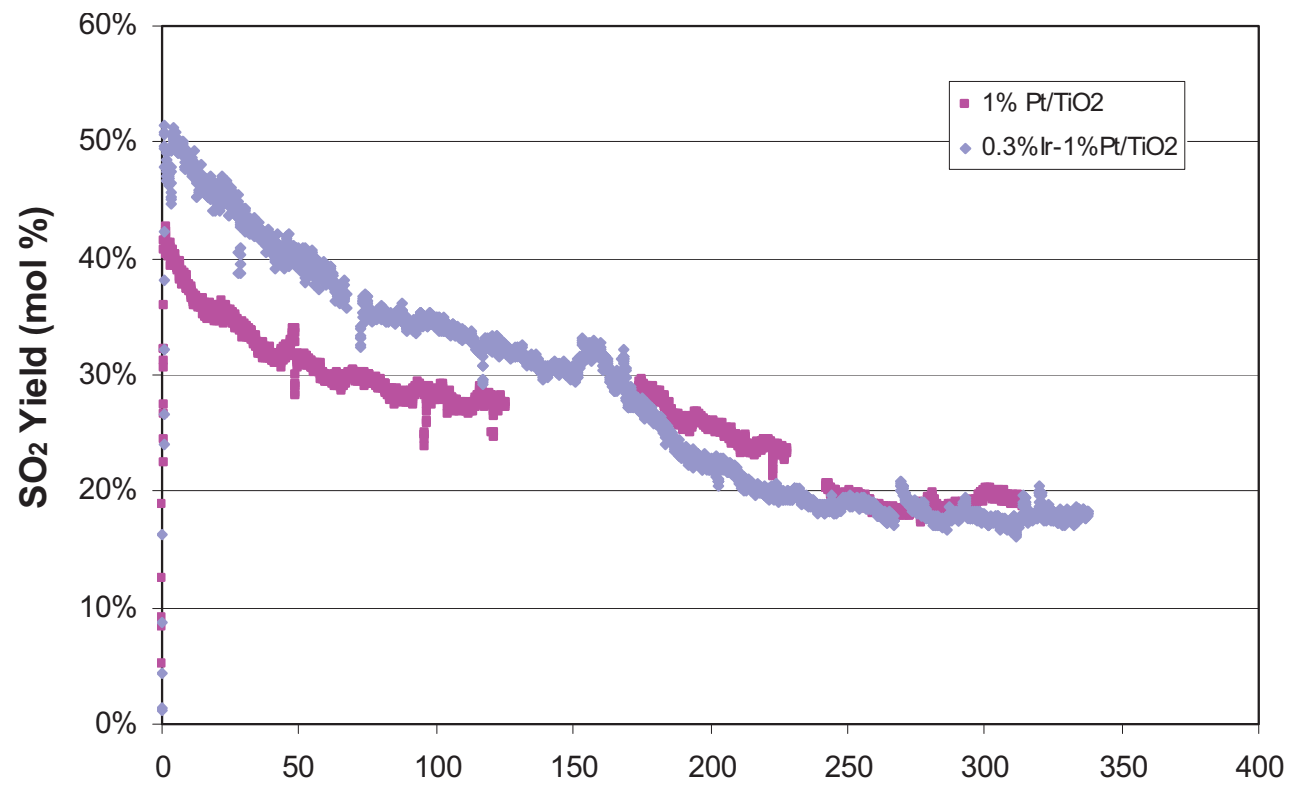

Figure 12. $\mathrm{SO}_{2}$ yields over $\mathrm{Pt} / \mathrm{TiO}_{2}$ and $\mathrm{Ir}$ stabilized $\mathrm{Pt} / \mathrm{TiO}_{2}$ catalysts at $30 \mathrm{bar}, 850^{\circ} \mathrm{C}, 78.4 \mathrm{wt} \% \mathrm{H}_{2} \mathrm{SO}_{4}$, and $\mathrm{a} \mathrm{WHSV}=120 \mathrm{~g} \mathrm{acid} / \mathrm{g}$ catalyst $/ \mathrm{hr}$. 


\subsection{Path Forward}

Any future work in this area should focus on developing stable catalysts for the sulfuric acid decomposition reaction operating at industrially relevant pressures. $\mathrm{Pt} / \mathrm{TiO}_{2}$ catalyst may still be stabilized with Ir or $\mathrm{Ru}$, but at different concentrations. The INL procured $\mathrm{Pt} / \mathrm{TiO}_{2}$ catalyst with varying amounts of Ir and Ru. Catalysts include $1 \mathrm{wt} \% \mathrm{Pt} / \mathrm{TiO}_{2}$ with $0.1,0.2,0.3$, and $0.4 \mathrm{wt} \%$ of Ir or $\mathrm{Ru}$. A second set of catalysts include $1 \mathrm{wt} \% \mathrm{Ru}-0.3 \mathrm{wt} \% \mathrm{Pt} / \mathrm{TiO}_{2}$ and $1 \mathrm{wt} \% \mathrm{Ir}-0.3 \mathrm{wt} \% \mathrm{Pt} / \mathrm{TiO}_{2}$ samples. These catalyst samples should be examined for the acid decomposition reaction at elevated pressures. Platinum group metals supplied in a wire gauze configuration may be more stable because the bulk phase metals would not be susceptible to particle growth. Additionally, metal oxides and complex metal oxide catalysts may show promise as highly stable, highly active materials. 


\section{PUBLICATIONS AND PRESENTATIONS}

Ginosar, D. M., H. W. Rollins, L. M. Petkovic, K. C. Burch, and M. J. Rush, "High-temperature sulfuric acid decomposition over complex metal oxide catalysts" International Journal of Hydrogen Energy, Vol. 34, 2009, pp. 4065-4073.

Petkovic, L. M., D. M. Ginosar, H. W. Rollins, K. C. Burch, C. Deiana, H. S. Silva, M. F. Sardella, and D. Granados. "Activated Carbon Catalysts for the Production of Hydrogen via the Sulfur-Iodine Thermochemical Water Splitting Cycle" International Journal of Hydrogen Energy, Vol. 34, 2009, pp. 4057-4064.

Rashkeev, S. N., D. M. Ginosar, L. M. Petkovic, and H. H. Farrell, "Catalytic activity of supported metal particles for sulfuric acid decomposition reaction," Catalysis Today, Vol. 139, 2009, pp. 291-298.

Ginosar, D. M., L. M. Petkovic, K. C. Burch, S. N. Rashkeev, and H. H. Farrell, "Platinum group metal catalysts for hydrogen production via the sulfur based thermochemical water splitting cycles," $21^{\text {st }}$ North American Catalysis Society Meeting, Paper OC47, San Francisco, CA, June 8-12, 2009.

Ginosar, D. M., L. M. Petkovic, H. H. Farrell, K. C. Burch, Y. Wang, and S. N. Rashkeev, "Metal Oxide Catalysts for Sulfur-Based Thermochemical Water Splitting Cycles," Session INOR 443, $237^{\text {th }}$ ACS National Meeting \& Exposition, March 22-26, 2009, Salt Lake City, UT.

Ginosar, D. M., L. M. Petkovic, H. H. Farrell, and K. C. Burch, "Recent progress in catalyst development for hydrogen production in the sulfur-iodine thermochemical water splitting cycle," American Institute of Chemical Engineers Annual Meeting, Philadelphia, PA, November 16-21, 2008.

\section{REFERENCES}

1 H. Tagawa and T. Endo, "Catalytic decomposition of sulfuric-acid using metal-oxides as the oxygen generating reaction in thermochemical water splitting process," International Journal of Hydrogen Energy, Vol. 14, 1989, p. 11.

2 S. Zhao and R. J. Gorte, "The effect of oxide dopants in ceria on n-butane oxidation," Applied Catalysis A-General, Vol. 248, 2003, p. 9. 